\title{
Reflecting on dilemmas in digital resource design as a response to COVID-19 for learners in under-resourced contexts
}

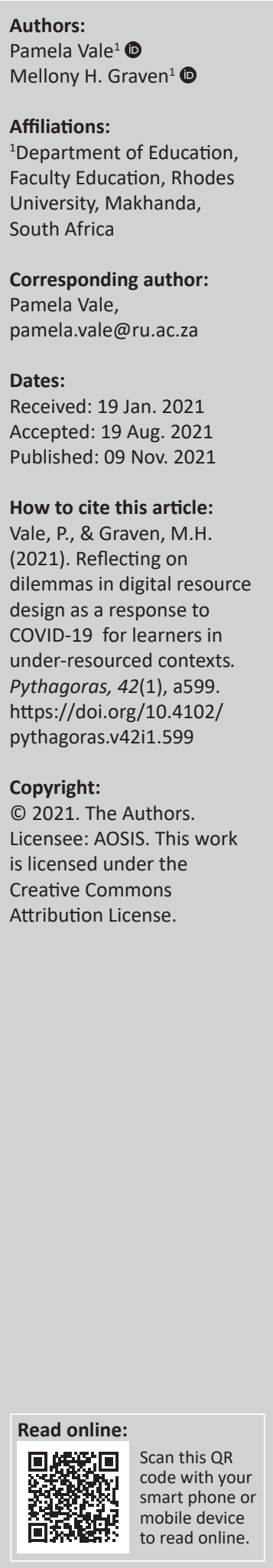

The coronavirus disease 2019 (COVID-19) pandemic and the resulting school closures in South Africa necessitated a major shift in how to support learners' ongoing mathematics learning. For 10 weeks learners were strictly confined to their homes with restrictions that prohibited seeing any person outside of their household. The only means to access learners and parents in their homes was to reimagine our South African Numeracy Chair Project work and transform it from predominantly face-to-face interventions to digital modalities. As a result, we initiated a project of digital resource development and distribution, particularly focused on our local community in the Eastern Cape. Twentytwo existing resources and 36 purpose-designed resources were shared via Facebook. Through in-depth post hoc reflection of the rapid digitalisation of our materials and ways of working we address these questions: (1) In relation to learners' new 'ecology of learning' during lockdown what digital access modality and platforms were most fit-forpurpose in sharing mathematics learning resources? (2) What principles informed resource design and adaptation for digital distribution and use? (3) What dilemmas were confronted in making decisions about resource design and distribution?. These questions are answered through a document review and post hoc reflections on the noted dilemmas. We share some feedback received and discuss implications of our work and the dilemmas confronted for the provision of quality digital resources for supporting mathematics learning in historically disadvantaged and under-resourced communities in a post pandemic world.

Keywords: South Africa; COVID-19; digital resources; task design; ecology of learning; underresourced communities.

\section{Introduction}

The coronavirus disease 2019 (COVID-19) pandemic and the resulting school closures in South Africa necessitated a major shift in how to imagine providing support for learners' ongoing mathematics learning. Schools were closed from 18 March 2020, initially for a period ending on 14 April 2020. The announcement of a 21-day 'hard' lockdown (Stage 5) from midnight on 26 March 2020 represented the first extension of this closure. It was further extended to 30 April 2020, and again extended with slightly fewer restrictions (Stage 4) to 31 May 2020. This meant that for 5 weeks all learners were strictly confined to their homes (Republic of South Africa [RSA], 2020a). Schools remained closed for a further 5 weeks with restrictions remaining in place that prohibited learners from seeing any person outside of their household (Spaull \& Van der Berg, 2020). The strict regulations on movement of people during this time meant that no project or person could reach learners and parents in their homes to distribute much-needed numeracy and literacy learning resources.

It was only on 08 June 2020 that a staggered re-opening of schools began; however, another school closure was imposed from 23 July 2020. The revised plan for phasing grades back into schools was published on 02 August (RSA, 2020b) and had Grade 5 and Grade 8 returning to school as late as 31 August 2020. The number of school days available for instruction was significantly lower than the number scheduled on the pre-Covid-19 school calendar: Grade 5 and Grade 8 lost $42 \%$ and Grade 4 and Grade $939 \%$ of their official school days in the pre-COVID-19 calendar (Hoadley, 2020).

Note: Teaching and learning mathematics during the Covid-19. 
There was further loss of instruction time due to the timetable models promoted by the Department of Basic Education (DBE, 2020) in order to ensure social distancing. These included platooning (half of the school attending in the morning, and half in the afternoon); attending on alternate weeks, or days of the week; and a bi-weekly rotational attendance model (DBE, 2020). Schools that were able to maintain the strict social distancing requirements with all learners attending were permitted to do so (RSA, 2020c), but for the vast majority of schools this was not possible and as a result the remaining contact instructional time was effectively halved (Hoadley, 2020). Hoadley (2020) reports that of 7162 schools surveyed in August 2020, only $8 \%$ were able to accommodate all learners on a regular daily timetable. This schedule endured for the remainder of the school year and attendance remained extremely poor.

Van der Berg, Van Wyk and Selkirk (2020) explain that the learning losses for learners are likely to be longer than the tally of instructional days lost. While the extent of the learning losses is as yet unknown, Gustaffson and Nuga (2020) predict that Grade 12 outcomes could be below expectations for a period reaching as far forward as 2031, indicating the cumulative loss that young learners are likely to carry through their entire school journey. Hoadley (2020) explains that the disparities among households with regard to educational resources being available in the home, and the effects of the lockdown on food security and health, mean that the severity of the learning losses will 'map onto existing social and educational inequalities' (p. 8).

The South African Numeracy Chair Project (SANCP) aims to advance educational equity, particularly for learners in historically excluded communities and under-resourced schools. In South Africa, a society with an education system with deeply entrenched inequalities (Amnesty International, 2020), the gap will widen between under-resourced and wellresourced schools, and the harshest of the consequences of the school closures will be thrust on the most vulnerable learners. We have already seen this unfolding, locally and nationally (Batyi, Donyeli, \& Amner, 2020). Our SANCP work had since inception in 2011 used a dual resource-based and contactbased approach to school and community partnership work. This involved regular face-to-face professional development, learner mathematics clubs and family mathematics events, all accompanied by the provision of a wide range of physical research-informed resources. The SANCP resources are freely available for downloading from the project website, although our partners predominantly engage with project ideas through the use of physical resources provided during mediated faceto-face interactions in professional development sessions, clubs and community events. The pandemic demanded immediate reimagination of a digitalised way of supporting mathematics learning. Finding a creative strategy to access these learners in their homes became an urgent priority, and given the constraints presented by the hard lockdown regulations, the only option was to use a strategy built on digital networks. This required us to completely reimagine our work and use digital means for sharing learning resources.

Several dilemmas were confronted in the decision-making process of which digital modality to use, how to conceptualise what would be most useful to develop and how best to 'distribute' these. It required knowing and understanding some of the challenges of the living situations and limited resources of those we were supporting. This linked to considerations of what support would be easy to use and of educational value.

In terms of educational value SANCP resource design draws broadly on a socio-constructivist perspective on learning, which assumes that learners must actively engage with materials and ideas in order to construct knowledge and understanding. A framework of confronting dilemmas in the design of mathematics learning digital resources for use in under-served communities provides an analytic structure for this article.

The questions we address include:

- In relation to learners' new 'ecology of learning' during lockdown what digital access modality and platforms were most fit-for-purpose in sharing mathematics learning resources?

- What principles informed resource design and adaptation for digital distribution and use?

- What dilemmas were confronted in making decisions about resource design and distribution and how were these managed?

\section{Description of the South African Numeracy Chair Project COVID-19 digital resource drive}

The SANCP has been researching innovative, sustainable and practical solutions to the challenges of early numeracy education since 2011. The focus of the model that the project works to is one of blending research and development (Graven \& Venkat, 2013). Learners and teachers in historically disadvantaged public primary schools in the Eastern Cape are the primary focus of SANCP work.

All SANCP numeracy intervention programmes with teachers, learners, parents and other community members are anchored by relationships built and nurtured through face-to-face events and activities. While, since 2011, we have made considerable effort to create and maintain virtual communities through our website and Facebook page, and our virtual 'members' have expanded well beyond our Eastern Cape partners, our development work has mostly focused on in-person contact and sustaining communities whose membership involve physical presence and participation in the joint enterprise (Wenger, 1998) of each intervention rather than managing 'virtual' communities. The SANCP website has served largely as a repository of 
resources that teachers continue to access post interventions for classroom resources, and the Facebook page has provided a means of sharing feedback, news and information about events. Our usual way of working with teachers, learners and parents was completely halted by lockdown regulations, and our use of online platforms, in particular, needed to be immediately repurposed.

In response, we initiated a project of resource development and distribution through digital means, specifically through social media. This project was implemented across the full 10 -week period of Stage 5 and Stage 4 lockdown. It was particularly focused on our partner communities in Makana and Ndlambe municipalities (although the resources were available, and were used, far beyond that). In total, 22 existing SANCP resources and 36 new purpose-designed primary mathematics resources were created and shared digitally from March to June 2020 on a near-daily basis. The resources included: problem-solving activities, games, puzzles and fluency practice. Resource design was guided by our socioconstructivist perspective of learning which assumes that students must be actively engaged with materials to construct their own understanding and that mathematical proficiency requires developing conceptual understanding, strategic competence, procedural fluency, adaptive reasoning and a productive disposition (Kilpatrick, Swafford, \& Findell, 2001). Different types of resources focused on different combinations of these strands of proficiency.

For our local mathematics clubs and schools, we delivered a range of mathematics workbooks for home use but these supplementary physical provisions are not a focus of this article.

Our choice of platform was Facebook in particular, in part because we could already reach our existing 1951 followers from the first day, and there was great potential to grow beyond that number. We explore this fully later in this article. The purpose of the Facebook page thus shifted from being a platform we used to share news and information to a platform through which we could reach learners and parents in their homes and provide access to quality resources.

\section{Theoretical and conceptual framework}

In this article, we share several dilemmas that informed our choice of digital modality, design principles and distribution. Dilemmas have been used by several mathematics educators as a structuring device for post hoc reflection on design issues for a range of mathematics education interventions and practices (Adler, 1998, 1999; Graven, 2005). They argue that the articulation and theorisation of the dilemmas and tensions we face in the design of interventions and in our broader work is an important and necessary part of our praxis as teacher educators. Dilemmas provide a useful tool for conscious reflection on challenging and complex aspects of our practice.

In terms of our perspective on learning, and theoretically framing the study as noted above, our work draws largely on a socio-constructivist perspective of learning and our notion of mathematical proficiency is shaped by Kilpatrick et al.'s (2001) five strands of mathematical proficiency (also evident in our South African primary curriculum documents). Conceptually we draw on the work of Watson (2004) in defining and delineating the 'ecology of learning', and on the work of Greeno (1998) in reflecting on the affordances and constraints that this ecology presented in relation to intervention through digital modalities. Digital modalities are here defined as the digital technologies and tools that can be used for online teaching and learning (Shank, 2020). Our chosen access modalities were mobile devices and the digital platform chosen was Facebook.

In reflecting on the design process, we use De Lange's (2015) distinction between slow and fast design, and his explanation of the role of various types of intuition. In order to structure our description of the design principles, we use the structure offered by Barbosa and De Oliveira's (2013) five 'arenas of conflict' (p. 545): context, language, structure, distribution and levels of interaction. We use this frame in a similar manner to Sullivan, Knott and Yang (2015) who reflected on these as dilemmas faced by task designers in the process of deciding between alternatives. Within this discussion, we explain how the decisions we made worked to leverage affordances offered by the learners' new ecology of learning in terms of digital access.

Watson (2004) uses the metaphor of the classroom as an ecology of participation:

It is a system which offers certain kinds of interactions as possibilities (teachers talking to learners, learners talking to each other), with normal practices which are somehow regulated ... and within which individuals interact in ways which themselves influence the development of the system. (p. 24)

Watson (2004) further explains that she defines 'ecology' as an environment in which:

Elements, human and non-human, physical and semiotic, interact with each other in ways which result in change or perpetuation of the environment and the elements and relationships within it, rather than solely of the individual elements. (p. 24)

The school closures and the nature of the staggered return of grades with rotational timetabling meant that the primary site of learning for school learners shifted, and the 'ecology of learning' (Watson, 2004) was fundamentally changed. For the initial 10 weeks of school closures the site of learning was exclusively the home. For the 5 weeks of 'hard' lockdown in particular, it was not possible for teachers or education development partners to distribute physical resources or learning materials to learners in their homes due to the restrictions on movement for all people. 
The SANCP provision of support to learners (and teachers and parents) now inhabiting this new 'ecology of learning' required careful consideration of the affordances and constraints presented by it, particularly in relation to the use of digital modalities in the home. Greeno (1998) explains that attunement to affordances and constraints, which includes understanding 'well-coordinated patterns of participation in social practices, including ... interactional conventions of communities' (p. 9), is important for those providing resources for practices. As designers of resources and the means of their distribution, it was critical for us to understand these patterns and conventions within the ecology. We use the language of 'affordances' and 'constraints' in reflecting on this ecology, seeing affordances as 'qualities of systems that can support interactions and therefore present possible interactions for an individual to participate in' (Greeno, 1998, p.9) and constraints, as 'norms, effects and relations which limit the wider possibilities of the system' (Watson, 2004, p. 23).

\section{Research method and design}

This article emerges from our qualitative case study that post hoc reflects on (and analyses) dilemmas addressed in the digital drive to distribute resources during Stage 5 and Stage 4 lockdown. Our methodology involved first a document review conducted prior to (and continuously throughout) the digital design project, and secondly post hoc reflection on several design dilemmas confronted in resource design in relation to the new ecology of learning context reviewed primarily in documents.

\section{Document review}

Given the sudden lockdown and the urgency of our response we focused on data that could be gathered quickly enough to inform our decisions on digital transformation of mathematics learning support. Document review provided immediate sources of data that informed our planning and reflection on dilemmas confronted. We begin by describing the new 'ecology of learning' that learners moved into during the first 10 weeks of lockdown as gathered from a range of documents and secondly what digital modality and platforms are available in our historically disadvantaged and underresourced Eastern Cape community - as available through documentary review.

As a research and development project, interventions like this resource drive are not initiated without first carefully considering all available, relevant information. It is also essential to keep up to date in situations that are as unstable as was the case during the lockdown; therefore, the document review continued throughout the 10 -week period. Because the focus was on the provision of learning resources to the homes of learners attending schools and programmes run by our education partners, the document review focused on the Makana and Ndlambe municipalities in the Eastern Cape.

Every Government Gazette documenting the COVID-19 regulations was analysed and all notices issued to schools by the DBE and the Eastern Cape Department of Education (ECDoE) that pertained to lockdown were analysed (up to 01 June 2020). All Grocott's Mail (the local newspaper) articles describing the lockdown situation for the Makana community were also analysed. Document review continued throughout the project as government decisions were continually updated and new advice given to schools throughout 2020. For example, the initial plan was to share one existing resource per day for 21 days; however, as soon as it became clear that the lockdown and school closures would be extended, the plan shifted to designing new resources and managing them more strategically.

Also included in the document review were reports that allowed us insight into the affordances and constraints to learning through digital platforms that might be presented by conditions in the home, as this would become the learners' 'ecology of learning'. The specific reports consulted are (see full details in references):

- Amnesty International (2020). Broken and unequal: The state of education in South Africa.

- Goldstuck, A. (2020). Under the skin of social media in South Africa. In Patricio, O. (Ed.), SA Social Media Landscape 2020: Social Media Myths, High Walls and Controlled.

- Human Sciences Research Council (2014). State of poverty and its manifestation in the nine provinces of South Africa.

- Kemp, S. (2020). Digital 2020: South Africa.

- Makana Municipality. (2018). Final Makana Municipality Integrated Development Plan 2019-2020.

- Ndlambe Municipality. (2018). Integrated Development Plan 2019/2020 (Final Review).

- StatsSA. (2012). South African Population Census 2011. Accessed March 5, 2020 from https://wazimap.co.za/ profiles/district-DC10-sarah-baartman/

- StatsSA. (2018). Community Survey 2016.

- StatsSA. (2020a). General Household Survey 2019.

- The Broadcast Research Council of South Africa. (2019). The Establishment Survey.

The StatsSA documents were particularly valid for analysis as most of the other documents we included all quoted statistics derived from these reports. Furthermore, reliability of this data is strong and information is publicly available and accessible. The Quarterly Labour Force Survey (StatsSA, $2020 b, 2020$ c) is particularly relevant and is quoted as it describes the context for South Africans during lockdown. All the above-mentioned documents were reviewed and collated for answering the research questions.

We acknowledge that there are several pitfalls in the use of post hoc reflections as data (Shanks, 2017).

Cognition and intuition are notoriously difficult to capture. However, through the articulation of various dilemmas confronted and analysing the decisions made in relation to those dilemmas one is able to provide a coherent and useful 
account of praxis that should inform future grappling with the digital age that the pandemic has brought centre stage into education across the globe. As Graven, Borba, Jablonka, Martin and Subramaniam (2021) state, the digital transition in education has recently gained speed due to the massive closure of, and disruption to, schools as a result of Covid across the globe. While online learning opportunities bring the possibility for increased access to quality mathematics education resources there is enormous unevenness in systemic and individual preparedness to optimise these opportunities. This unevenness plays out across countries and within countries and there is concern that the digital divide could exacerbate inequities across gender, social class and race.

Through purposeful and systematic reflection on dilemmas faced working in under-resourced contexts we contribute towards important conversations and considerations for ongoing digital transformation in mathematics education post the pandemic.

The design and implementation process of the SANCP resource drive was carefully planned and executed. While not at the time intended to be reported as research, it is a process and product worth interrogating. In order to enhance the reliability of the claims made here and the principles that are extracted from this process and reflection, earlier drafts of the resources, personal notes made while designing the resources, artefacts produced while testing the resources and the messages to parents that were shared with each resource were used as stimuli for recall. This reflection is aimed at responding to the third question of this article: What principles informed and underpinned the design of the resources developed? In order to provide a structure to this reflection and the report on the content of the reflections resulting from it, we use Barbosa and De Oliveira's (2013) five arenas of conflict that arise when making decisions during task design: context, language, structure, distribution and levels of interaction.

\section{Ethical considerations}

The Ethics in Health Research Report (Department of Health, 2015) indicates that when research depends on material that is already in the public domain and no human participants are involved it does not require any ethical clearance certificate from an accredited human ethics committee. This does not mean, however, that the study is exempt from adhering to ethical research principles. In the case of this research, all documents used in the document review are in the public domain and are easily accessible. The personal reflection on the design process is that of the first author as the designer of the materials and leader of the project. The authors have no conflict of interest and no commercial interest in the success or otherwise of the resources referred to here. All material is published under a Creative Commons AttributionNonCommercial-NoDerivatives 4.0 International licence, and as such is available for use and distribution by any person or organisation. Attributions are clearly indicated on resources where ideas were inspired by the work of other authors and organisations. No information is included from conversations with any individual, and only comments made in the public domain on our public Facebook page are mentioned, with no identifying information given in this article (though identifying information is in the public domain).

\section{Results and discussion: A displaced ecology of learning}

In this section, we present a description of the new 'ecology of participation' for learners. This description is based on the findings of the document review. First the community itself is described in terms of the demographics and other socioeconomic indicators. Then the focus turns to understanding aspects of the ecology of participation that offer affordances and present constraints specifically related to digital use.

The SANCP is located in Makhanda in the Eastern Cape one of the poorest provinces in South Africa (Human Sciences Research Council, 2014). The Eastern Cape has the largest number of persons and households reliant on social grants in South Africa (StatsSA, 2020a). In 2019, the percentage of learners in the province attending no-fee schools was $76.9 \%$ and $86.4 \%$ of all learners benefitted from school feeding schemes. Unemployment in the Eastern Cape during the period of hard lockdown was the highest of the nine provinces (StatsSA, 2020b), and it is the Eastern Cape that has been hardest hit by job losses in 2020, with employment decreasing by $13.5 \%$ between the first and third quarters of 2020 (StatsSA, 2020c).

Food security immediately became a priority concern during lockdown (MacLennan, 2020), with learners unable to access their school nutrition programmes, and household income impacted by rapidly rising unemployment and the loss of all opportunities for casual work. Dr Imtiaz Sooliman of Gift of the Givers was quoted as saying that he witnessed 'the worst amount of hunger in the 28 years of the Gift of the Givers' when distributing food aid in the Eastern Cape in July 2020 (Nortier, 2020).

In particular, our work is focused in certain wards of the Makana and Ndlambe municipalities. The school situations of the learners and teachers that we work with are well known to the SANCP team. The home circumstances of the learners, however, are less understood as we have worked, even with parents and guardians, predominantly through school-based events. In planning for distribution of resources into learners' homes, it was important to gain as clear an understanding of the home circumstances as possible. In the context of lockdown, the most accessible source of this information was from statistical publications.

The communities we focused this intervention on are those in wards that feed the schools and educational programmes that we work with as SANCP. The information that was sought included first the size of the target population, number 
TABLE 1: Demographics of the target communities.

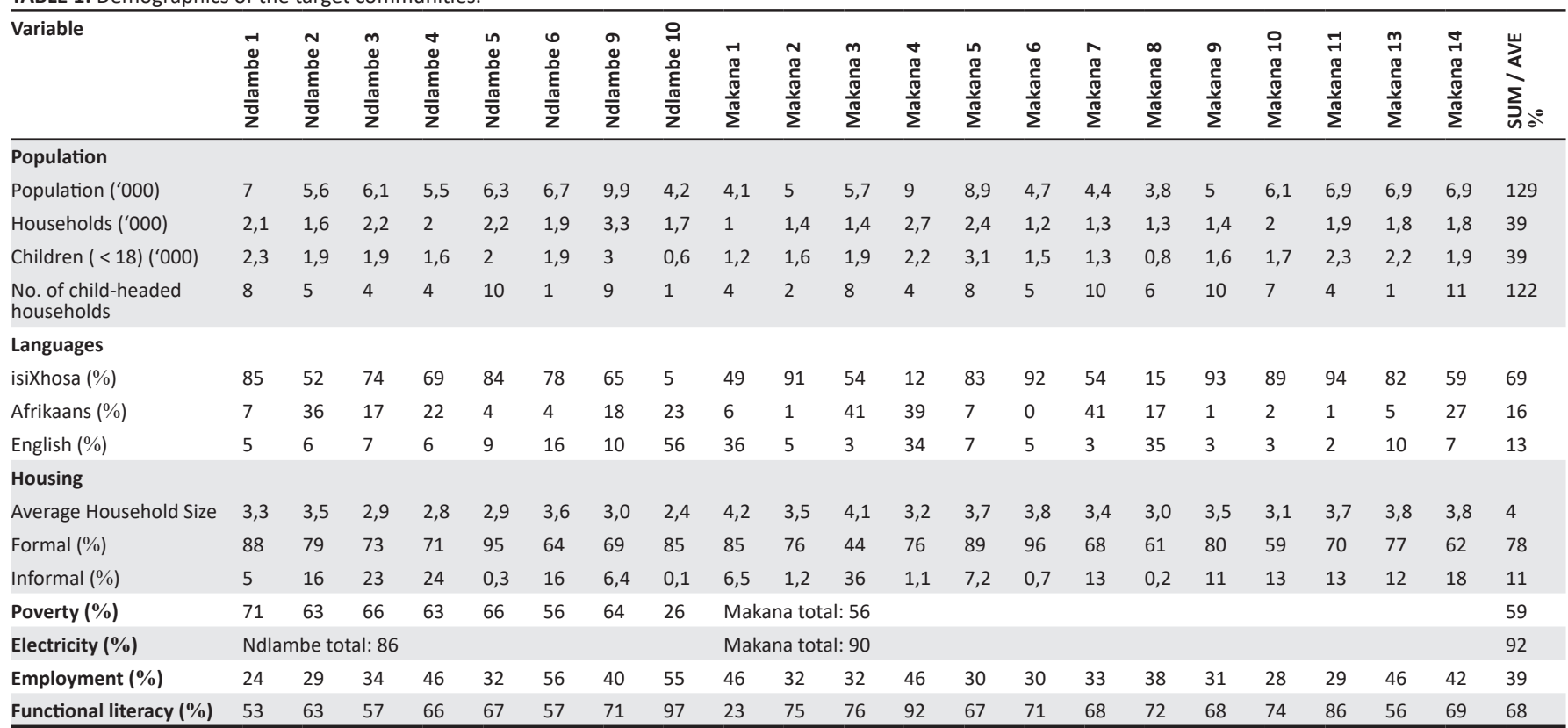

Source: Eastern Cape Socio Economic Consultative Council, 2017; Makana Municipality, 2018; Ndlambe Municipality, 2018; StatsSA, 2012, 2018, 2020a

of households in these target areas and number of learners in this population. This information would allow us a sense of the size of the population and a glimpse into the home to see who the other members of each household were likely to be, as these would be the people that learners would interact with as they learned. The full set of this data is provided in Table 1 . The table was constructed using the most up-to-date statistics available per category (Eastern Cape Socio Economic Consultative Council, 2017; Makana Municipality, 2018; Ndlambe Municipality, 2018; StatsSA, 2012, 2018, 2020a).

\section{Broader community statistics}

The total population that we were targeting in this intervention consisted of 128912 individuals, of which there were 38735 learners (<18 years) and 38515 households. This area included 58 public primary schools and 2 independent primary schools, 33 of which SANCP has had involvement with during the past 10 years.

Only $22 \%$ of these schools are fee-paying schools, and most of the 58 schools are served by a school nutrition programme. A further four of the remaining schools are also supported by this programme. The lockdown context therefore undermined the food security of a staggering number of households as this nutrition was not available.

As a measure of the economic status of these communities, we sought information on the percentage of adults (aged 18-64 years) who were employed. This allowed a glimpse into the possible food security of the community and generally whether the possibility would exist that there was disposable income to purchase books, learning resources, data or digital devices. We also sought information on the level of poverty in each community. Poverty was defined as the proportion of the population living on R800 ( \pm US\$60) or less per month. Additional information that we sought included the types of dwellings in the community and whether these dwellings had access to electricity. Formal dwellings were defined as those built according to approved plans (StatsSA, 2020a), while informal dwellings are shacks that have been erected on land that has not been planned for housing. Electricity provision was necessary to consider as the success of any digital resource drive depends on the ability to charge the devices.

The percentage of adults with employment ranged from $24 \%$ to $55 \%$ across wards. The likely implication of this is that within households it is more likely than not that there is a working-age adult dependent in addition to child dependents and elderly members of the household. Household disposable income could not be expected to exist, let alone stretch to purchases of learning materials. This is also reflected in the proportion of households living in poverty in this community. It varies widely across wards, with Ndlambe ward 10 being as low as 26\%. For the remaining areas, however, this percentage ranged from $56 \%$ to $71 \%$.

This picture of a significantly economically strained community seemed to offer only constraints; however, the high rate of electricity provision opened the possibility that digital devices may be present in the home. Most dwellings were also formal, although this varied across wards. Formal housing would afford learners a more conducive environment for learning than informal homes like shacks.

\section{Data on household composition}

Household composition was also an aspect to consider. Rather than being in a classroom with 40 other learners and a qualified teacher, the ecology of learning for each child during hard 
lockdown included the other members of their households. Without being able to do a survey of the households that our learners were in, the COVID-19 context allowed us only to search public documentary sources available online. We sought the most recent statistical reports, particularly relying on the General Household Survey (StatsSA, 2020a) for the Eastern Cape statistics. For the Makana and Ndlambe region in particular, we relied on the most recent municipal reports (Makana Municipality, 2018; Ndlambe Municipality, 2018). Unfortunately, the latter two reports were not as recent as the StatsSA data, but they do provide a sense of the context that could reasonably inform the decisions we made.

We sought statistics on household size, generational composition, and whether learners were living with their parents or not. The approximate literacy rate and educational level attained by the adults in the community was also important to research, as younger learners in particular would require the guidance of an adult in the home to facilitate their engagement in the learning tasks. The home language of the population was also relevant to inform the design of the resources. We also needed to ascertain the level of support required for the adults who would be engaging in the learning tasks with their learners - particularly for Foundation Phase learners.

The average household size for the homes in our community was calculated as 4 (see Table 1). The General Household Survey (StatsSA, 2020a) expands this information to show the proportions of households at various sizes in the Eastern Cape: $22.1 \%$ of households have only 1 person, $36.8 \%$ have 2-3 people, $24.7 \%$ have $4-5$ people and $16.5 \%$ have 6 or more household members. The breakdown of household composition by generations is given as: $34.5 \%$ being double generation households (learners and their parents), $18.4 \%$ are triple generation households (grandparents are part of the household) and $8.5 \%$ are skip generation households (learners living with their grandparents) (StatsSA, 2020a). In addition, statistics are available about whether learners live with their parents. As many as $34.6 \%$ live with neither parent and $35.4 \%$ live with just one parent (only 3.2\% live with just their father). What can be hesitantly inferred from these statistics is that many homes may have only one adult with a number of learners making up the remainder of the household. Double generation households are most common $(34.5 \%)$, and a high percentage of households have a single parent (35.4\%).

This holds both affordances and constraints. For learners living in homes with other learners, learning and play can occur between learners. Where an older sibling is present it is possible that the older child could assist a younger learner with understanding and using the digital resources. The educational attainment of the adults in the household is relevant here. The more educated the adults present in the household, the more likely that they are able to help their learners to work with the digital resources. The presence of an older child, or a literate adult, available to interact with the child as they work with the digital resources would make it possible for the child to work in the zone of proximal development (Vygotsky, 2012). The assistance of this more knowledgeable individual would mean that the child could learn and develop rather than just be practising content that they have already mastered.

Functional literacy is defined as an adult who has completed Grade 7 (or higher) (Eastern Cape Socio Economic Consultative Council [ECSECC], 2017). Across the Makana and Ndlambe communities this varies widely from as low as $23 \%$ to as high as $97 \%$. The literacy rate is also lower for older adults, implying that grandparents in the home are less likely to be literate. In some areas, it seems likely that a literate adult is present in the home and can assist learners in navigating digital learning resources, but for many this may not be the case. A related statistic is that $65 \%$ of adults with learners in the home never read to them and $58 \%$ of adults live in homes with zero books (South African Book Development Council, 2016).

\section{Affordances and constraints presented by this new 'ecology of learning'}

In relation to the envisioned drive to get digital learning resources into homes, the general data on the targeted community and the households within it hint at the following affordances and constraints to this project.

\section{Affordances:}

- If a device capable of receiving digital resources is in the home, there is most likely electricity to keep it charged.

- Most housing is formal, which is a setting that is more likely to be conducive to learning as compared to informal housing.

- The functional literacy of adults in the home is high in some areas, meaning that an adult could assist a younger learner in understanding the activities described in the digital resources.

- In hard lockdown, adults were unable to attend work, making them available to help facilitate their child's learning. Most households had at least one adult.

\section{Constraints:}

- The employment rate is low in most areas, and the poverty rate is high. The food security crisis in the Eastern Cape during lockdown (MacLennan, 2020) would be impacting these households. Food security concerns could understandably override concerns for continuing education in the early stages of lockdown.

- The functional literacy in a number of areas is low and so it is possible that some learners do not have a literate adult to assist them in understanding the resources and how to use them.

- The population we hoped to reach is large both geographically and in numbers. The digital platform chosen needed to allow efficient contact with a large (preferably limitless) group. 
TABLE 2: Access to internet and other modalities for learning support in target communities.

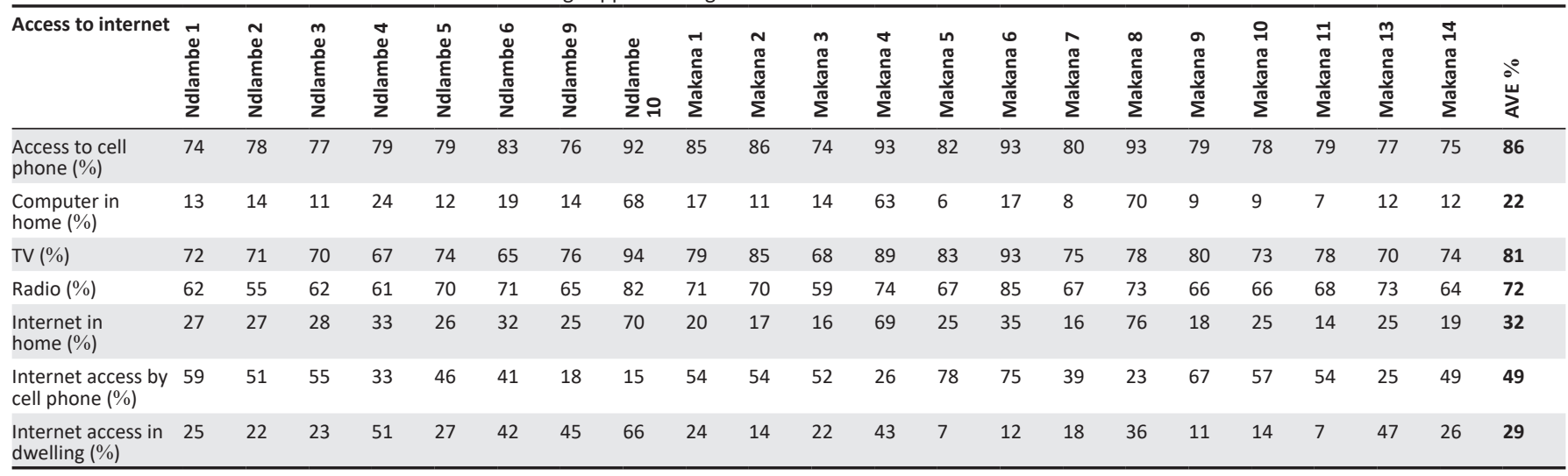

Source: Eastern Cape Socio Economic Consultative Council. (2017). Makana local municipality socioeconomic review and outlook, 2017. East London: ECSECC; StatsSA. (2012). South Africa Population Census 2011. Retrieved from https://wazimap.co.za/profiles/district-DC10-sarah-baartman/; StatsSA. (2018). Community survey 2016. Pretoria: Department of Statistics, South Africa.

\section{Results and discussion: Digital affordances and constraints}

In order to make the best possible decision about which digital access modality to select, and which platform would be most suitable, our document review included mining information about household access to various technologies for each of the municipal wards in which SANCP works directly. This varied widely between wards, and so an average was calculated across these wards to guide our thinking and decision-making.

\section{Selecting an access modality: Cell phones}

The ECDoE (2020a) issued an instruction:

Learners and their parents/care-givers are requested to access the teaching and learning resources being made available on different digital platforms to ensure learners keep up to date with their schoolwork. (p. 1)

These platforms included live streams and radio and television broadcasts, as well as an online repository of resources on the DBE website (https: / www.education.gov. $\mathrm{za}$ /covid19supportpackage.aspx). All of these require certain devices and technologies to be available in the home, and in the case of the online resources, a measure of digital literacy. The ECDoE also issued instructions to principals in March 2020 to send learning materials like reading books and textbooks home with learners, as it was already thought likely that remote learning may continue for longer than initially thought. In the Eastern Cape most schools have learners sharing such resources in the classrooms, and thus there are not sufficient materials for each learner to take books home (Amnesty International, 2020). Printed learning materials could therefore not be assumed to be available to our learners, supporting our conviction that intervention was needed.

Hoadley (2020) describes the provincial responses to the shift to remote learning as being largely web-based, and states that initial efforts at providing television and radio offerings was piecemeal, uncoordinated, poorly publicized and for the lower grades especially, unconnected to the curriculum' (p. 15). Spaull and Van der Berg (2020) also point out that these broadcasts only targeted Grades 10-12 and early childhood development, which meant that support for Grades R-9 was solely web-based. As is evident in the data in Table 2, an average of only $22 \%$ of households across the Makana and Ndlambe communities had access to a computer in the home, which is necessary for optimal use of web-based resources. The most accessible technology was cell phones, with $86 \%$ of households having access to at least one cell phone. In addition, the prevalence of smartphones rather than ordinary cell phones is rising steadily, although there would still be a minority of these $86 \%$ of households who would have a phone that will not access the internet (The Broadcast Research Council of South Africa, 2019). Televisions and radio were present in most households; however, as noted by Hoadley (2020), the quality and relevance of the resources provided through those channels was poor. Creating content to broadcast such learning support is also beyond what SANCP was able to consider doing at the time, and these activities take time. What we needed was quick access.

The relatively high percentage of cell phone access afforded us the opportunity to reach the widest possible 'audience' if we were to select this as our access modality (Cabello, Claro, Rojas, \& Trucco, 2020). A constraint presented by this approach was the relatively low percentage of dwellings with internet access. Most people were accessing the internet from outside the home (StatsSA, 2020a), and these spaces were inaccessible during lockdown. However, of those households with access to the internet, an average of $49 \%$ did so via a cell phone. At the time of planning this resource drive the percentage of mobile connections as a proportion of the total South African population was 176\% (103.5 million mobile connections) and $70 \%$ of these connections were broadband (Kemp, 2020), which would allow a good, stable connection to use digital learning resources. This high number however is not evenly distributed across the population with many wealthier South Africans and businesses having multiple connections. Being one of the poorest provinces, the Eastern Cape would likely have a 
much lower proportion of these connections than most other provinces. This said, it is an encouraging sign that access to the internet may be slightly better than the General Household Survey (StatsSA, 2020a) indicates.

Only $37 \%$ of the population were social media users (Kemp, 2020); however, with $62 \%$ of the South African population being internet users, there is the possibility for this percentage to grow significantly (Kemp, 2020).

\section{Selecting a digital platform: Whatsapp vs Facebook}

Having decided to focus on cell phones as the dominant access modality, a choice had to be made about the particular platform to use. Cell phones do provide several constraints regarding what technologies are possible to use. Many stateof-the-art learning technologies exist if one has access to high-speed internet and a computer. Video-conferencing platforms like Zoom enabled some teachers to reach learners during school closures, learning management systems like Moodle assisted schools to distribute lessons and resources, and websites with structured learning experiences, like Khan Academy, were popular. None of these was feasible for efficient use with cell phones. Cabello et al. (2020) explain that effective use of cell phones in learning is constrained by their small screen size, relatively slow browsing capabilities and low storage capacity.

In selecting a digital platform to use it was also necessary to consider affordances from other parts of the system. In Makhanda, there were several efforts to support learners' continued learning initiated by Rhodes University, among others. There were also several stories of creative initiatives by local teachers to reach their learners. Many local teachers almost immediately connected with their classes by creating WhatsApp groups (Batyi et al., 2020) and other local organisations created WhatsApp groups for early childhood development practitioners and parents in order to share learning ideas and resources. These practitioners in turn created groups with the families they worked with.

WhatsApp is an instant messaging platform that does not require particularly sophisticated digital literacy - in South Africa it is the most used application among people with both higher and lower digital literacy (Goldstuck, 2020). It also uses comparatively little data to share images, videos and audio and is thus the most economically accessible of the available options, as reflected in it being the most popular messaging app across all income groups in South Africa (Goldstuck, 2020). In 2020, WhatsApp had 10.1 million highly active users in South Africa and it was the most used application among city, town and township populations, and across all age demographics and race groups (Goldstuck, 2020).

Teachers across the country soon formed WhatsApp support groups to share resources with one another (Feldtman, 2020) but soon met the group capacity imposed by WhatsApp of
256 members. These groups largely migrated to using the Telegram app (Feldtman, 2020), which allows a wider range of file types, of larger sizes, to be shared and the group size can be as large as 200000 members. WhatsApp groups initiated by our partnership with local teachers were small enough to avoid being constrained by the 256-member limit, but it did not meet our requirements. The hope was for our digital resource drive to reach as many of the approximately 40000 learners (StatsSA, 2012) in the wards that SANCP works in as possible in their homes, and a group size of 256 members would soon be insufficient. Telegram is also a relatively new application that has not yet been widely taken up. It is currently used by just $1 \%$ of social media and instant messaging users in South Africa (Goldstuck, 2020) and it was also therefore unsuitable.

Facebook provided the most affordances for our purposes. Its highly active user base is second only to Whatsapp, and as a social networking application it has the highest network usage in South Africa (Goldstuck, 2020). It is also of relevance to our purposes that, despite the higher data usage of the Facebook app, it remains second only to WhatsApp in usage across all income groups in South Africa. Facebook has no limitation on the number of people that can 'follow' a page and allows posts to be shared to other pages. Our existing Facebook page already had 1951 followers who would immediately gain access to the resources. Additional affordances included the possibility of sharing all resources with other community Facebook groups. One Facebook group for Makhanda residents has 39800 members, another three groups in Ndlambe each have 2060 members, 3100 members and 4300 members.

Given the constraint that WhatsApp presents in terms of group size, and the affordance offered by Facebook to reach a far larger number of homes, Facebook was our chosen primary platform for this resource distribution drive. The SANCP community of teachers had also already started building smaller WhatsApp groups for their classes, and the possibility existed to leverage this as an affordance to reach more homes. Teachers are more likely to have access to Facebook and the internet, and so the possibility existed that they could save the resources and distribute them to the homes of their learners through WhatsApp. The possibility of this cross-platform use informed the design of the resources and our system of managing the resources we shared.

\section{Summary of constraints and affordances and the related decisions}

The decision-making process about which access modality to use, and which digital platform to use, is summarised in Figure 1. Affordances and constraints are indicated by $(+)$ and (-) symbols, and the decision is indicated in green.

In Figure 1, we include the first decision that needed to be made: how to get numeracy resources into homes. The two options were to delay our response until it became possible 


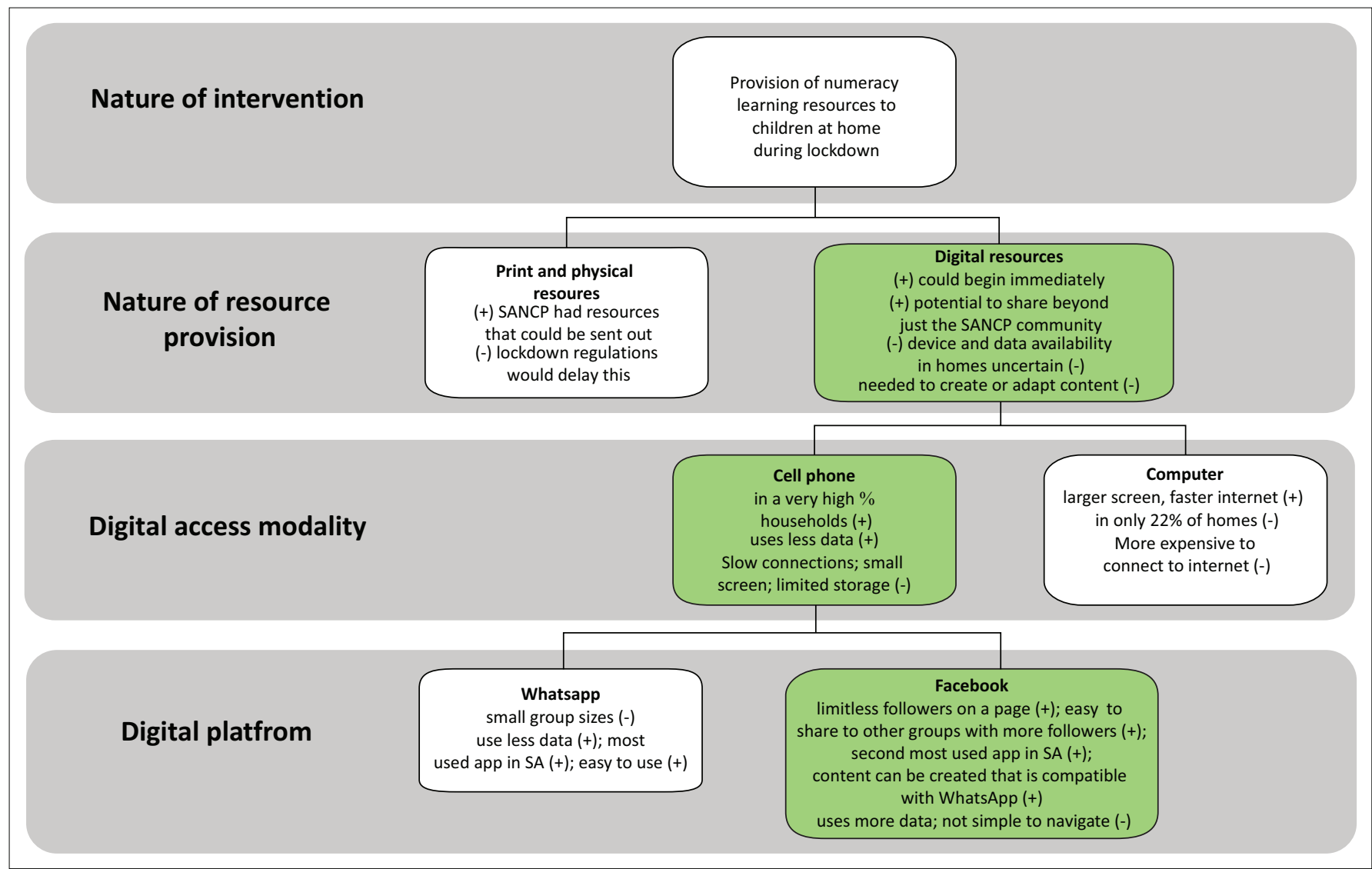

FIGURE 1: Digital decision-making process including constraints and affordances.

to distribute resources that were already purchased, or to proceed with an immediate response, which would involve extensive content development. Initially the decision was to pursue the former, but as it became evident that the twoweek school closure would extend to 21 days, the appropriate decision was clear - digital distribution of resources. The SANCP did have a bank of resources, but these needed adaptation for these purposes. The 'ready-to-use' (with minor adaptation) resources were also insufficient to see us through the 21 days, if resources were posted every day as we had hoped to be able to do. When those 21 days became 10 weeks, a significant demand for more content arose. In the following section, we present a post hoc reflective description of the design process, particularly describing how the first author strived to maintain attunement to the affordances and constraints already outlined here. We will also attempt through this discussion to highlight the design principles followed and will share the tools used to achieve all this.

\section{Discussion: The process and principles of digital resource design}

In total, there were 12 existing SANCP resources that could be shared through our Facebook page as is, with only minor adjustments to make them work for Facebook. The project began on 26 March with a post sharing the MathsUp cell phone application designed for Grade $\mathrm{R}$ learners. It is a cell phone app, designed according to the South African curriculum and optimised to use minimal data. This sort of post fit perfectly with the type of content we envisioned sharing. Our aim with the digital resource drive was to share one numeracy resource per day of lockdown. It was only as we reached 03 April 2020 that we realised that far more resources were needed and creativity was required to make the resources appealing to both parents and learners. We compared and explored resource-sharing posts from previous years and analysed the nature of those that received the most attention and positive feedback.

The number of people reached in the early posts shared in this digital drive remained relatively low during the first two weeks when sharing existing resources that had not been designed for this particular purpose. This caused a need for a pause to reflect on how to increase the reach of these resources. Digital resources were not reaching sufficient homes, and the homes they were reaching were largely from metropolitan areas, and not the community we were targeting.

To address these concerns, plans were made to create content specifically for the purposes of sharing digitally via Facebook, with capabilities of being used across device types (cell phones, tablets, computers) and across different media platforms (including WhatsApp). The hope was that these resources would be attractive, mathematically conceptually sound, curriculum aligned, and so forth. Figure 2 shows parts of the resources provided.

De Lange (2015) writes that it is close to impossible to write about the design process in task design as it requires meta- 

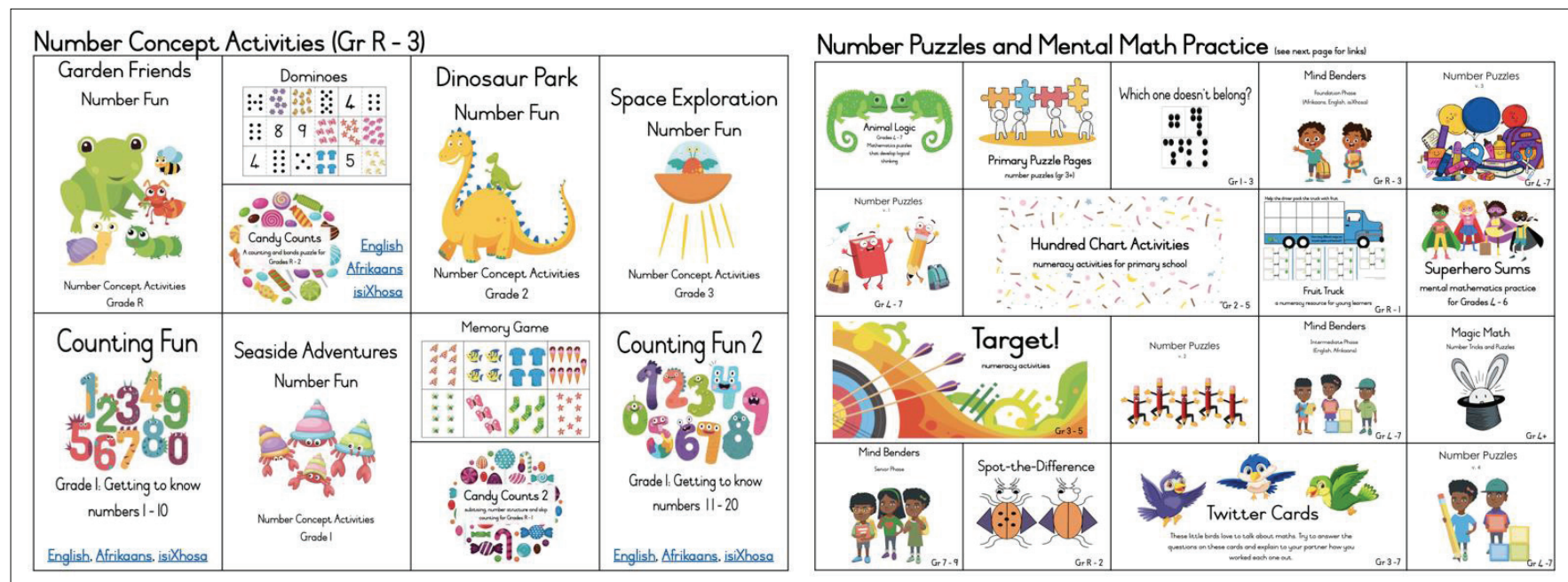

FIGURE 2: Front covers of a range of the resources developed and shared.

cognitive access to mental processes, in this case from the past. It was possible to clearly map out the data used from the document review to decide on the modality and platform in focus, as these were carefully stored in computer files and notes, and the documents are still easy to gain access to online. However, the process of attempting to illuminate the design process and decisions is more challenging. It requires deep reflection and, fortunately, reflective notes made during the design process and all previous drafts of the resources have been saved as stimuli for further reflection.

An explicit choice was made to focus here on literature about mathematical task design, rather than literature about mathematical resource design, as the 'child engaging in the task at home' was foremost in the mind of the designer during the process. We do here refer to 'resources', but these 'resources' contained minimal instructive material (if at all). Rather, they presented almost exclusively tasks for learners to engage in. Resource here refers to a collection of mathematical tasks.

De Lange (2015) makes a distinction between slow design and fast design. Slow design is the ideal process when designing mathematical tasks: it is based on developmental research and generates high-quality evidence of its effectiveness and is guided by principles that inform every step of the process. This type of design relies on freedom of choice, freedom of time, freedom to explore and freedom of thought (De Lange, 2015). It is not often the case that these conditions coalesce to permit this type of design process. Fast design is a feature of our highly commercialised society, where products are created under time pressure, without the necessary care that would produce high-quality mathematics resources - rather it is the aesthetic appeal that is foregrounded (De Lange, 2015). Without a doubt, it was fast design that was needed, but rather than being a thoughtless process, much detailed consideration was given to the design of the tasks. We will reflect later on the improvements we would make, as the speed of the process meant that some compromise was necessary, but there is a process that can be reflected on and presented here.

One aspect of the challenge in documenting this process is the role of intuition as a form of rapid cognition (De Lange, 2015). Intuition would seem to be a cognitive process that defies explanation; however, De Lange (2015) refers to strategic intuition as a type of intuition. He explains:

[S]trategic intuition is not a vague feeling, like ordinary intuition. Strategic intuition is a clear thought. And it's not fast, like expert intuition. It's slow. That flash of insight you had last night might solve a problem that's been on your mind for a month. And it doesn't happen in familiar situations, like a tennis match. Strategic intuition works in new situations. That's when you need it most. Strategic intuition can be characterized by thinking, not feeling, informed by experience, leading to a deep insight that connects seemingly unrelated knowledge to create new insight and 'gestalts' in unfamiliar, new, situations. Strategic intuition is, in my opinion, a crucial factor in the art of educational design in mathematics and science. The problem seems to be that for obtaining strategic intuition, the crucial factor is time, especially reflective time. (pp. 295-296)

Strategic intuition was certainly relied on in the design process. While the lockdown regulations caused an urgency to the work, the stalling of other aspects of normal daily work and life allowed the designer the mental space to become immersed in the process, and continually reflect - each day something learned from the previous day could be acted upon to inform the next resource and posting. This process was supported by reflecting on the engagement statistics available from Facebook, or comments by users, and reflecting on difficulties with technologies used to create the resources. Thus, even with the need for 'fast design', the lockdown circumstances allowed for immersion in the project and did permit, although in a concentrated period of time, several strengths of the slow design process.

The broadest guiding principle in the creation of these resources was that the majority should address the 'Numbers, Operations and Relationships' part of the 


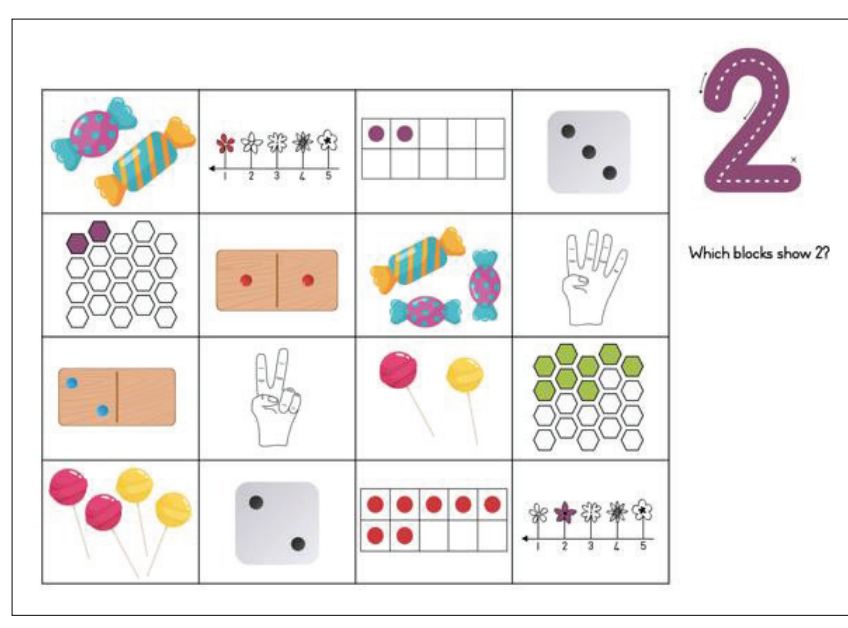

FIGURE 3: Sample of an early number concept activity requiring minimal reading.

mathematics curriculum as it has the greatest weighting of all the content areas of the curriculum (DBE, 2011). It is the number sense developed through these activities that other topics in mathematics rely upon. Learners with an 'absence of a coherent development of number sense' (Graven \& Venkat, 2013, p. 16) struggle with mathematics in later grades.

The 'strategic intuition' mentioned above was not in the absence of a guiding mathematical learning theory. As noted above, the sociocultural perspective that guides all the SANCP work guided the design, as did Kilpatrick et al.'s (2001) five proficiency strands. The designer aimed to address all of the five strands across the tasks. The strands are interwoven, in the same way that Kilpatrick et al. describe them, but certain types of tasks foregrounded one or two strands. Resources comprising problem-solving tasks were particularly aimed at encouraging the development of strategic competence, adaptive reasoning and productive disposition. There were also resources for younger learners that comprised tasks that aimed to facilitate their development of conceptual understanding of number (such as those presented in Figure 3). In addition, there were tasks included in many of the resources that required practice in working with a number of similarly structured problems to promote the development of procedural fluency. All the resources, and the tasks within them, were designed with the development of 'productive disposition' in mind. The resources were designed to be enjoyable and attractive, with the hope that learners would choose to engage with the tasks therein.

The following sections provide a more structured reflection (by the first author as the designer of the resources), using Barbosa and De Oliveira's (2013) five 'arenas of conflict', but in a similar way to Sullivan et al. (2015)'s application of this framework. These sections will be written in the first person as they comprise the post hoc reflections of the first author. This 'arenas of conflict' framework is applied to structure these post hoc reflections as it is closely related to the categories of 'requirements' generated for the resources. Sullivan et al. describe the arenas of conflict as dilemmas.

\section{Context as dilemma}

This dilemma refers to decisions made about the context of the tasks themselves, and whether one opts to use reality, or semi-reality, or a pure mathematics task (Sullivan et al., 2015). In order to grant the learners using the resources a more accessible, and relatable, point of entry to the tasks, the characters were always racially diverse learners when I opted to have human characters. I also made use of anthropomorphised objects (e.g. pencils), or animals, aliens, robots, dinosaurs, etc. These were chosen for their visual appeal and their cultural neutrality. Part of the reason for this was that it is very difficult to find high-quality illustrations of diverse people, and so my preference was to use attractive illustrations available of other types of characters.

The majority of the contexts used were semi-real in nature. I wanted to appeal to the playfulness of learners, and their rich imaginations, in order to entice them to engage with the resources. These semi-real contexts included imagining oneself to be a robot designer and using arrays in their design, or learning number 'tricks' to become a magician, or being immersed in the themed resources that used gardens, the seaside, dinosaurs and space travel as the context for the mathematical tasks or even helping superhero cats to catch stars. I did not want the resources to feel 'school-like' as far as possible. I wanted a child to choose to investigate what was happening in the resources.

There were also resources that were mathematical without links to a context. The series of 'Number Concept' resources for young learners were some of those. In these resources, numbers were presented in a variety of representations and were used in matching games, or puzzles, or number concept mats. For the older learners, in Intermediate Phase, there was less use of contexts and many resources contained number puzzles for them to solve. There were four arithmetic puzzle books that were developed.

\section{Language as a dilemma}

Language is a difficult dilemma to navigate when designing resources at speed within South Africa's multilingual context. English is overwhelmingly the preferred language of learning and teaching (LoLT) in South Africa, despite it being the native language of less than $10 \%$ of the population (Robertson \& Graven, 2015). In the Makana and Ndlambe contexts, schools teach in English (a minority choose Afrikaans) from Grade 4 onwards, and many primary schools opt to have Foundation Phase learners also learn in English, despite the official policy advocating for mother tongue instruction in the early years (DBE, 2010). The demographic data in Table 1 shows that the vast majority of the community is isiXhosa speaking, and English is the language of the smallest group. When one adds to this the relatively low percentage of functionally literate adults in this community it is clear that language is indeed a dilemma, and this before the dense and complex nature of mathematical language is considered. 

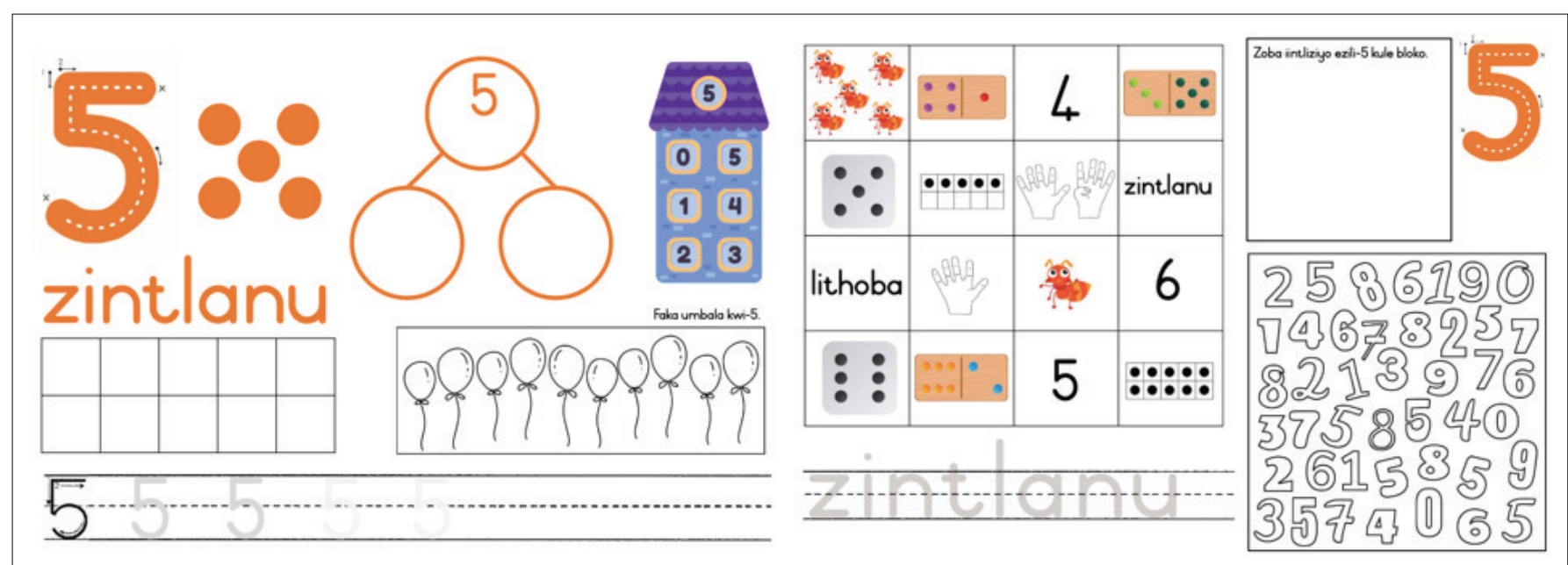

FIGURE 4: Samples of early number concept activities that have been translated.

In the lockdown context it was not possible to contract someone to do translations of the materials from English into isiXhosa and Afrikaans; however, where this was possible it was done. The Number Concept resources for young learners, for example, were either available in all three languages or were designed to have minimal language. Figure 3 shows an example of a resource where the language required is minimal, and Figure 4 shows a translated version of a task from a resource in this same series.

As far as possible, resources for the Foundation Phase had little to no text. For the Intermediate Phase, when learners could be expected to have at least a basic ability to read in English, more text was incorporated, although there were always activities within the resources that did not require understanding of the text in order to interpret the task.

\section{Structure as a dilemma}

This dilemma refers to the degree of openness of the tasks, for example whether there are multiple solutions to a problem, or whether there are a variety of methods of finding the solution, or even whether the learner themselves is required to pose the problem. Because one of the overarching desires in the creation of these resources was for learners to engage deeply with the mathematics, the majority of the tasks had no prescribed method for solving the problem. There were some numeracy games that had rules, like the board game included in the dinosaur-themed resource, and such activities were generally more prescriptive, but most resources, particularly for the Intermediate Phase, were puzzles that were nonroutine and required learners to devise their own methods. The arithmetic puzzle books are examples of this. It was also a deliberate design decision not to include introduction of algorithms in any of the resources. All the activities were at their core exploratory and promoted playful learning and urged learners to really think and devise strategies.

\section{Distribution as a dilemma}

Distribution as a dilemma refers to how to select the content of the tasks and the cognitive demand of these tasks. As explained above, the focus was to be predominantly on 'Numbers, Operations and Relationships', although there were four resources that addressed 'Space and Shape' for some variation and for some creative exploration. Another aspect of distribution was the grades that would be catered for. The initial plan was for Foundation Phase and Intermediate Phase resources to be shared on alternating days; however, as the project progressed it was clear that the Foundation Phase resources were most needed as the engagement with those posts, and the downloads of the materials, was extremely high. The Foundation Phase resources were regularly reaching more than 10000 Facebook users. Three even reached over 35000 users. It became clear that prioritising this level would thus be beneficial. As a result, I created Intermediate Phase resources that would realistically take a few days to complete (e.g. the puzzle books and the Mind-Bender books with Olympiad questions included) so that I could focus on releasing Foundation Phase resources more frequently.

Regarding the cognitive demand of the tasks, I included a variety of levels of tasks, so that each resource could reach a range of ability levels. There were activities that learners at lower grades in the phase, or lower levels of mathematical knowledge, could engage in, as well as more cognitively challenging tasks for learners who were ready to attempt them. It should be noted that each resource is a multi-task resource, and so a range of tasks was included each time.

\section{Levels of interaction as a dilemma}

Levels of interaction as a dilemma refers to considerations of who the participants would be. In this new learning ecology that learners had moved into, this became parents, grandparents, siblings and other adult household members. From the review of the demographics, I could not assume anything about the literacy of the adults in the home, and thus had to consider that the young learner may need to engage in the tasks without the mediation of a literate adult. I designed the resources with the hopeful assumption that other household members might also engage in the activities, 
which is the reason for the occasional inclusion of board games or interactive possibilities, like that of the magic tricks that a child could do with someone else. The resources and tasks were as language-free as possible, although this was not always possible and there are resources that required some reading, like the two 'Math and Art' resources. These were aimed at older Intermediate Phase learners, however, who would more likely have been able to engage with tasks without adult assistance.

I could also make no assumptions about the mathematical knowledge of the other members of the household, particularly the knowledge of how to interact with a child around these activities. To this end, the aim of the tasks was clearly stated, and there were always explanations included in the Facebook posts, and on the resources, as to what level the resource was appropriate for. In addition, some of the Foundation Phase resources also contained more detailed explanations to the parents about how and why an activity should help their child to learn.

A related issue was that the tasks had to be designed to require no resources other than the digital image. Without this consideration, no interaction would be possible. Because most mobile users would not be able to print the resources out and do the activities on paper, most of the tasks were easy to sketch if necessary and complete with just a pencil and paper, for example a number pyramid, using the picture on the cell phone as a reference. It was difficult to eliminate the need for paper and a pen or pencil, and so it is needed for many of the resources. Where this could be avoided, however, it was. It was critical that the activities not require any more resources than that, as none could be guaranteed to be in the home. For example, where dice were needed, learners were advised to write the numbers 1 to 6 on scraps of paper and then draw one out each time they had a turn.

\section{Choice as a dilemma}

There is another dilemma that I would like to add: that of designing the resource and task in a way that invites the child to choose to engage in it. The new ecology of learning that learners were thrust into had a critical individual absent - the teacher. In a classroom, there is a teacher managing the learning process, and directing the learners to do certain activities, and monitoring whether this is done. It is common to hear teachers bemoan the fact that so few learners do their homework. The resources that were created for this digital drive had to make the child want to look at it and want to engage with it. In the absence of the structure that school provides, the child would largely need to choose to learn.

The aesthetic design of the resources is very deliberate. They incorporate bright colours, attractive characters, a clean and neat layout, and high-quality images wherever possible. This seems a superficial concern, but if the child chooses to look away rather than to examine and explore what is happening on the screen, then the resource is worthless. Considerable effort was put in to ensure that the resources looked as professional as possible. This required the acquisition of many new computer skills and much patience. The effort has been worthwhile as much of the praise from parents of the resources has been for their attractiveness. If this alone encourages them to download and use it, then it was well worth that attention to detail, even while it had mostly nothing to do with the mathematics itself.

\section{Resource management as a dilemma (and some technical possibilities)}

The final dilemma that I needed to carefully think through and refine the strategy through much trial and error was regarding how to manage the vast number of resources that were accumulating. In this section I describe the technicalities of managing this process in order to provide an example of how to manage digital resources in such a way that there is a useful repository accessible, and so that the resource can be shared on a variety of platforms and devices.

Each resource that was shared was available to download through a link posted either in the body of the post, or as the first comment on the post. Facebook sometimes will not allow sharing of a post if its algorithms identify a link as being to a third-party site. Sharing the link in the comments was possible however. Every downloadable document was a PDF, so that the formatting and design remained unchanged for people opening them on different systems. The link was only useful to individuals who had a computer to view the document on, however. In order to make it accessible to everyone, every page of the resource was saved as an image, by taking a screenshot, and it was shared as part of the Facebook post as a picture. This meant that even mobile users could scroll through the pictures linked to the post. This also allowed a user to save the picture onto their cell phone, and share it on other applications, like WhatsApp.

A technical issue that needed resolving was how to share the link, and how to store the documents so that they remain accessible at that link. I initially saved each document on Google Drive, but despite setting the documents up as public documents, there was repeatedly feedback from users who could not access them. I reverted to using box.com (www. app.box.com) which allowed anyone with the link to reliably download the resource. It is completely free to use and is easy to navigate. The next challenge was to shorten the URL that linked to the Box account, as it was extremely long and did not work well on Facebook. I used another free application, bitly (www.app.bitly.com) to create shorter URLs. I created a (free) account and can log in and find all of the 122 links I created during this project, thus enabling me to reuse them. In addition, it keeps a tally of the number of downloads of each file, which is a useful analytic in evaluating the effectiveness of this digital resource drive. A last tool that I found useful was a PDF compressor. Because of the number of images and objects in the documents, the PDF files were extremely large and would require a large amount of data to download. The free online tool at ilovepdf.com (https:// www.ilovepdf.com/compress_pdf) was the fastest and most 
effective of those that I tried. The PDFs were then a more reasonable size to download.

A final, crucial, aspect of resource management is copyright. As the SANCP we publish every resource we develop under a Creative Commons Attribution-NonCommercialNoDerivatives 4.0 International licence. This allows users to copy and distribute the resources, although not for financial gain. This requires great care to be taken in the design of the resources, however, as all content must be original, or correctly attributed to the source that inspired it where relevant, or explicit permission should be granted to use it. This presented a particular challenge to the design, as any pictures that were used needed to be similarly shared under a Creative Commons licence, or a licence purchased for their use. The website www.freepik.com was chosen for this project as it included free images of diverse learners, and when you download any free image there is a licence issued that specifies that the image can be used to create documents to be shared. There is a premium membership option, which I opted to use so that I could get access to the larger library, but the free images are perfectly adequate and are of a good quality.

\section{Feedback}

The digital resource drive was extremely well received and reached a number of homes beyond what we had hoped for. The Facebook page grew from just 1951 followers, to over 5000 followers by the end of the 10-week period, and we received overwhelmingly positive feedback. Currently (June 2021) the page has 5470 followers. A word cloud was generated by copying all of the 313 comments on the Facebook posts into the online utility at www.wordclouds. com. An image is generated by calculating the frequency of each word used to determine the size of the font. It is interesting to note the prominence of words referring to the aesthetics of the resources (cute, beautiful, colours), and it is encouraging to see the words 'fun', 'helpful', 'sharing' and of course 'thanks'.

We did have requests for resources in isiXhosa and Afrikaans. This was certainly a weakness in the project. During that phase of the lockdown it was not possible to organise extensive translations. This is being addressed, however, with translations of the Foundation Phase and Intermediate Phase resources currently underway.

\section{Conclusion}

As of 29 April 2020, distribution of teaching and learning support materials was classified as an essential service (RSA, 2020d), which enabled more direct support to be provided to homes. This, combined with the permission granted to aftercare and enrichment centres to reopen (ECDoE, 2020b) and the naming of newspapers as an essential service (RSA, 2020e), meant that we became able to distribute resources to learners in their homes through the local newspaper, Grocott's Mail, and through our partner schools and aftercare centres. We were able to reformat most of the resources shared online into newspaper spreads that were delivered to homes and schools. The design principles followed in creating the digital product also served this printed product well and they have been distributed into more than 9000 homes in the Makana and Ndlambe municipalities - our SANCP communities.

While this article presents a somewhat different type of research data, it aims to capture our response as mathematics educators to a very particular moment in education in South Africa, when we needed to completely reimagine how we worked to support learners in their mathematics learning (and work at speed in this process). The article makes a novel contribution to informing possible ways forward in mathematics education as the pandemic continues and in a post-pandemic world. There are many advanced learning management systems and technologies that would have allowed for a smooth transition to remote learning, as we saw happen in many of the affluent independent schools in South Africa, but this is not the reality for the majority of the South African population (Pournara \& Bowie, 2020a). What this article offers is an approach to thinking through the provision of resources that is particularly sensitive to the realities facing impoverished communities. It is by no means an ideal solution and the framing of the post hoc reflection as a navigation of dilemmas captures that through making certain choices one must accept certain challenges to arise in relation to those choices. In particular, we note that more grappling with providing online learning resources to communities who need it most is required as many aspects of our response still exclude some households. This said, the article models a way of thinking through the pressing problem of how to educate learners when the primary site of learning is displaced into homes where food security is a prominent concern, and there are few resources for learning. The pandemic is by no means over, but once the COVID-19 crisis is under control, we will still have to contend with the severe suffering of many South African communities, and the vast inequalities in our education system will have widened. What this time has forced upon us is the urgency of reimagining our role as educators and as organisations that support education. There has been much creativity and innovation evident and the hopeful message would be that perhaps the pandemic is the 'unexpected catalyst' (Pournara \& Bowie, 2020b, p. 6) that forces us to learn from our collective work at supporting parents, carers and teachers to ensure the continuing mathematics education of their learners through the pandemic.

\section{Acknowledgements Competing interests}

The authors declare that they have no financial or personal relationships that may have inappropriately influenced them in writing this article.

\section{Authors' contributions}

P.V. contributed by writing the article, reviewing the literature, collecting data and analysing data. M.G. contributed to the conceptualisation of the article, discussions 
on the analysis of the data and revisions made in light of the reviewer comments.

\section{Funding information}

This work is based on the research supported by the South African Research Chairs Initiative of the Department of Science and Technology and the National Research Foundation (Grant No. 74658).

\section{Data availability}

The data that support the findings of this study are available from the corresponding author, upon reasonable request.

\section{Disclaimer}

The views and opinions expressed in this article are those of the authors and do not necessarily reflect the official policy or position of any affiliated agency of the authors.

\section{References}

Amnesty International. (2020). Broken and unequal: The state of education in South Africa. London: Amnesty International.

Adler, J. (1998). A language of teaching dilemmas: Unlocking the complex multilingual secondary mathematics classroom. For the Learning of Mathematics, 18(1) secondary mathematics classroom. For the Learning of $\mathrm{M}$
24-33. Retrieved from http://www.jstor.org/stable/40248258

Adler, J. (1999). The dilemma of transparency: Seeing and seeing through talk in the mathematics classroom. Journal for Research in Mathematics Education, 30(1), 47-64. https://doi.org/10.2307/749629

Barbosa, J.C., \& De Oliveira, A.M. (2013). Collaborative groups and their conflicts in designing tasks. In C. Margolinas (Ed.), Task design in mathematics education: Proceedings of the International Commission on Mathematical Instruction Study 22 (pp. 541-548). Oxford: ICMI. Retrieved from http://hal.archives-ouvertes.fr/ hal-00834054

Batyi, U., Donyeli, L., \& Amner, R. (2020, May 25). Lockdown widens the gap for Makhanda learners. Grocott's Mail. Retrieved from https://www.grocotts.co. za/2020/05/25/lockdown-widens-the-gap-for-makhanda-learners/

Cabello, P., Claro, M., Rojas, R. \& Trucco, D. (2020). Children's and adolescents' digital access in Chile: The role of digital access modalities in digital uses and skills. Journal of Children and Media, 15(2), 183-201. https://doi.org/10.1080/1748279 8.2020 .1744176

De Lange, J. (2015). There is, probably, no need for this presentation. In A. Watson \& M. Ohtani (Eds.), Task design in mathematics education: An ICMI study 22 (pp. 287-310). Cham: Springer.

Department of Basic Education (DBE). (2010). The status of the language of learning and teaching (LOLT) in South African public schools: A qualitative overview. Pretoria: DBE.

Department of Basic Education (DBE). (2011). Curriculum and assessment policy statement: Foundation phase mathematics. Pretoria: Department of Basic Education.

Department of Basic Education (DBE). (2020). Guidelines for development of the school timetables reopening of schools COVID-19. Pretoria: Department of Basic school timetal

Department of Health. (2015). Ethics in health research report 2015. Pretoria: Department of Health.

Eastern Cape Department of Education. (2020a, April 06). Instruction note 10 Curriculum support during COVID-19. Bhisho: Eastern Cape Department of Education.

Eastern Cape Department of Education. (2020b, June 02). Instruction note 23 Prevention and management of coronavirus (COVID-19). Bhisho: Eastern Cape Department of Education.

Eastern Cape Socio Economic Consultative Council. (2017). Makana local municipality socioeconomic review and outlook, 2017. East London: ECSECC.

Feldtman, J. (2020, May 20). Online teacher collaborations boom under lockdown. Grocott's Mail. Retrieved from https://www.grocotts.co.za/2020/05/20/onlineteacher-collaborations-boom-under-lockdown/.

Goldstuck, A. (2020). Under the skin of social media in South Africa. In O. Patricio (Ed.), SA social media landscape 2020: Social media myths, high walls and controlled data (pp. 52-61). Sandton: Ornico \& World Wide Worx.

Graven, M. (2005) Dilemmas in the design of mathematics in-service teacher education. R. Vithal, J. Adler, \& C. Keitel (Eds.), Researching mathematics education in South Africa: Perspectives, practices and possibilities (pp. 206-233). Cape Town: HSRC Press.
Graven, M., Borba, M., Jablonka, E., Martin, D., \& Subramaniam, K. (2021). Plenary panel 2: Mathematics education reform post 2020: Conversations towards building back better. Retrieved from https://www.icme14.org/static/en/news/35. html?v=161828 4987943

Graven, M., \& Venkat, H. (2017). Advocating linked research and development in the primary mathematics education landscape in contexts of poverty. In M. Graven \& $\mathrm{H}$. Venkat (Eds.), Improving Primary Mathematics Education, Teaching and Learning (pp. 11-24). London: Palgrave Macmillan.

Greeno, J. (1998). The situativity of knowing, learning and research. American Psychologist, 53(1), 5-26. https://doi.org/10.1037/0003-066X.53.1.5

Gustaffson, M., \& Nuga, C. (2020). How is the COVID-19 pandemic affecting educational quality in South Africa: Evidence to date and future risks. Stellenbosch: University of Stellenbosch.

Hoadley, U. (2020). Schools in the time of COVID-19: Impacts of the pandemic on curriculum. RESEP Non-Economic Working Paper. Stellenbosch: Research on Socio-Economic Policy.

Human Sciences Research Council. (2014). State of poverty and its manifestation in the nine provinces of South Africa. Pretoria: HSRC.

Kemp, S. (2020). Digital 2020: South Africa. Retrieved from https://datareportal.com/ reports/digital-2020-south-africa

Kilpatrick, J., Swafford, J., \& Findell, B. (2001). Adding it up: Helping children learn mathematics. Washington, DC: National Academy Press.

MacLennan, S. (2020, April 17). Volunteers step in as hunger hits home. Grocott's Mail. Retrieved from https://www.grocotts.co.za/2020/04/17/volunteers-stepin-as-hunger-hits-home/

Makana Municipality. (2018). Final Makana Municipality Integrated Development Plan 2019-2020. Makhanda: Makana Municipality.

Ndlambe Municipality. (2018). Integrated development plan 2019/2020 (final review). Port Alfred: Ndlambe Municipality.

Nortier, C. (2020, July 17). Court orders government to provide all school children with a daily meal. Daily Maverick, Coronavirus Daily Digest \#100. Retrieved from https://www.dailymaverick.co.za/article/2020-07-17-court-orders-governmentto-provide-all-schoolchildren-with-a-daily-meal/

Pournara, C., \& Bowie, L. (2020a, August 26). Salvaging the school year: Learning must continue for all, especially Grades 8 and 9 . Daily Maverick. Retrieved from https:// www.dailymaverick.co.za/article/2020-08-26-salvaging-the-school-year-learningmust-continue-for-all-especially-grades-8-and-9/

Pournara, C., \& Bowie, L. (2020b, August 12). COVID-19 disruption could be a chance to lay a firmer school maths foundation in South Africa. The Conversation. Retrieved from https://theconversation.com/covid-19-disruption-could-be-achance-to-lay-a-firmer-school-maths-foundation-in-south-africa-144083

Republic of South Africa. Department of Co-Operative Governance and Traditional Affairs. (2020a, 25 March). Disaster Management Act, 2002: Amendment of
regulations issued in terms of section 27(2). Government Gazette, \#43148. regulations issued in terms of
Pretoria: Government Printers.

Republic of South Africa. Department of Basic Education. (2020b, 02 August). Notice 411 of 2020: Disaster Management Act, 2002. Government Gazette, \#43578. 411 of 2020: Disaster Manageme

Republic of South Africa. Department of Basic Education. (2020c, 01 June). Notice 304 of 2020: Disaster Management Act, 2002. Government Gazette, \#43381. Pretoria: Government Printers.

Republic of South Africa. Department of Higher Education and Training. (2020d, April 29). Amendment of the directions issued in terms of Regulation 10(8) of the regulations made under Section 27(2) of the Disaster Management Act, 2002 (Act No. 57 of 2002). Government Gazette, \#43255. Pretoria: Government Printers.

Republic of South Africa. Department of Co-Operative Governance and Traditional Affairs. (2020e, April 29). Disaster Management Act, 2002: Amendment of regulations issued in terms of section 27(2). Government Gazette, \#43258. Pretoria: Government Printers.

Robertson, S.-A., \& Graven, M. (2015). Exploring South African mathematics teachers' experiences of learner migration. Intercultural Education, 26(4), 278-295. https:// doi.org/10.1080/14675986.2015.1071754

Shank, P. (2020, April 03). (The right) Learning modalities to deliver digital learning. Retrieved from https://elearningindustry.com/asynchronous-and-synchronousRetrieved from https://elearning
modalities-deliver-digital-learning

Shanks, D.R. (2017). Regressive research: The pitfalls of post-hoc data selection in the study of unconscious processes. Psychonomic Bulletin and Review, 24, 752-775. https://doi.org/10.3758/s13423-016-1170-y

South African Book Development Council. (2016). National survey into the reading and book behaviour of adult South Africans. Pretoria: South African Book Development Council.

Spaull, N. \& Van der Berg, S. (2020). Counting the cost: COVID-19 school closures in South Africa and its impact on children. South African Journal of Childhood Education, 10(1), a924.

StatsSA. (2012). South African Population Census 2011. Retrieved from https:// wazimap.co.za/profiles/district-DC10-sarah-baartman/

StatsSA. (2018). Community survey 2016. Pretoria: Department of Statistics, South Africa.

StatsSA. (2020a). General household survey 2019. Pretoria: Department of Statistics, South Africa.

StatsSA. (2020b). Quarterly labour force survey, Quarter 1: 2020. Pretoria: Department of Statistics, South Africa.

StatsSA. (2020c). Quarterly labour force survey, Quarter 3: 2020. Pretoria: Department of Statistics, South Africa. 
Sullivan, P., Knott, L., \& Yang, Y. (2015). The relationship between task design, anticipated pedagogies and student learning. In A. Watson \& M. Ohtani (Eds.), Task design in mathematics education: An ICMI Study 22 (pp. 83-114). Cham: Springer.

The Broadcast Research Council of South Africa. (2019). The Establishment Survey: March 2019 Release. Pretoria: Publisher Research Council.

Van der Berg, S., Van Wyk, C., \& Selkirk, R. (2020, November). Schools in the time of COVID-19: Possible implications for enrolment, repetition and dropout. Stellenbosch Economic Working Papers: WP20/2020. Stellenbosch: Department of Economics and the Bureau for Economic Research at the University of Stellenbosch.
Vygotsky, L. (2012). Thought and language. A. Kozulin, transl. Cambridge, MA: The MIT Press.

Watson, A. (2004). Affordances, constraints and attunements in mathematical activity. Research in Mathematics Education, 6(1), 23-34. https://dol. org $/ 10.1080 / 14794800008520128$

Wenger, E. (1998). Communities of practice: Learning, meaning, and identity. New York, NY: Cambridge University Press.

*Note: All of the resources referred to in this article are available at www.ru.ac.za and at https://web.facebook.com/RUSANC 